\author{
G. ULRICH GROSSMANN
}

\title{
El aura de la obra de arte y la desaparición del original
}

E N EL VERANO DE 2012 se llevará a cabo el 33 Congreso Internacional de Historia del Arte, en el Germanisches Nationalmuseum en Núremberg, con el título The Challenge of the Object ("El desafío del objeto"). El tema principal girará en torno al papel que desempeña hoy día el objeto en la historia del arte. ¿Qué se dice en la enciclopedias y en general en la bibliografía de historia del arte sobre el concepto objeto? Al revisar las enciclopedias especializadas sobre historia del arte se descubre con sorpresa que el término objeto casi no aparece en ningún lado, ni en el Wörterbuch der Kunst (Diccionario del arte) de Johannes Jahn ni en la Lexikon der Kunst (Enciclopedia del arte) de Olbrich, de I993; el mismo resultado se obtiene en los diccionarios en español, ${ }^{\text {I }}$ francés e inglés. La Lexikon des Mittelalters (Enciclopedia de la Edad Media) aclara el uso y la historia del concepto en la filosofía medieval, mientras que el Dictionary of art (Diccionario de arte) trata solamente sobre arte-objeto, respectivamente sobre el objet trouvé, así como sobre la utilidad de las piezas de uso práctico en el arte del siglo xx. Si se consulta esta bibliografía, se descubre que en la historia del arte no hay una definición del concepto objeto. Para lo cual es necesario recurrir a las

I. Esto se comprobó en 2 diccionarios en la red: el Diccionario de términos de arte y diseño (http://www.sitographics.com/dicciona/a.html) y el Diccionario histórico de arte (http://www. diccionariodearte.info/), consultados el i 6 de octubre de 20 I I. 
enciclopedias generales: en las alemanas, éste se define a través de la palabra Gegenstand, pero ésta sólo remite a la versión alemana del mismo concepto. ${ }^{2}$

Textos complementarios son aquí el Diccionario de la lengua alemana de los hermanos Grimm, así como la Enciclopedia británica en inglés. De acuerdo con el diccionario de los Grimm, el objeto es "un Gegenstand de la observación sensorial o mental; [se utiliza] como concepto filosófico en oposición al sujeto". 3 Por tanto, "objetivo" funcionaría como "figurativo", y en la actualidad se usa (sin basarse en el diccionario de los hermanos Grimm) más como neutral en oposición a subjetivo — aunque los académicos sabemos que esta modificación del concepto objetivo es incorrecta.

En la Enciclopedia británica de 2005 se remite al lector a la palabra objeto del siglo XIv. Ahí se establecen las siguientes definiciones: "I. algo material que puede ser percibido por los sentidos" (también un Gegenstand); "2. algo mental o físico a lo que se le dirige pensamiento, sentimiento o acción" (también un objeto de estudio); "3. la meta o final de un esfuerzo o actividad: propósito, objetivo"* (la meta de un esfuerzo —en alemán definición poco usual); "4. una cosa que forma un elemento de o que constituye el sujeto asunto de una investigación o ciencia” (objeto de investigación, tema de investigación); ${ }^{4}$ finalmente sigue una aclaración del significado gramatical, que aquí podemos dejar de lado.5 De forma similar se expresa el Grand Larousse.

¿Qué significa esto para el objeto en la historia del arte? A partir de estas definiciones, resulta claro que un objeto no es sólo el Gegenstand material, del cual nos ocupamos, sino también cada uno de los contenidos de nuestras materias, así como una obra de arte virtual o efímera, la historia de los artistas o

2. El término Gegenstand deriva originalmente de entgegen stehen (estar opuesto a) o también gegnerisch (contrario, con enemistad).

3. "ein Gegenstand der sinnlichen oder geistigen Betrachtung; als philosophischer Begriff im Gegensatz zum Subjekt”.

4. "I. something material that may be perceived by the senses", así como "2. something mental or physical toward which thought, feeling, or action is directed"; " 3 . the goal or end of an effort or activity: purpose, objective"* [* "Their object is to investigate the matter thoroughly [...] a cause for attention or concern 'money is no object"; "Su objeto es investigar el asunto a conciencia [... una causa de atención o preocupación 'el dinero no es objeto"” " 4 . a thing that forms an element of or constitutes the subject matter of an investigation or science”.

5. "5. Un sustantivo o su equivalente (como pronombre, gerundio o cláusula) que denote la meta o resultado de la acción de un verbo; un sustantivo o su equivalente en una frase preposicional" ("A noun or noun equivalent [as a pronoun, gerund, or clause] denoting the goal or result of the action of a verb; a noun or noun equivalent in a prepositional phrase”). 
la teoría del arte. Junto a los objetos materiales, los "pensamientos de nuestras representaciones en oposición al acto de lo representado"6 también pueden ser nuestro Gegenstand. Si usamos la palabra objeto en el sentido de "Gegenstand de la materia", podremos dejar el área de la materialidad y llegar a una definición válida en términos generales.

Bajo el título "The Lure of the Object" ("El atractivo del objeto"), se llevó a cabo en 2004 una conferencia en el Clark Institute en Williamstown, la cual inició Stephen Melville con las siguientes palabras: "los 'objetos' son de algún modo la cosa con la cual estamos dispuestos a decir que trabajamos"; 7 después distinguió al objeto de las "cosas", ya que veía ese concepto más en la filosofía, la teología y el folclor.

En síntesis, un objeto es la obra de arte, sin importar las propiedades de los materiales, y el Gegenstand (asunto) material o inmaterial de nuestra área de estudio.

Si hasta ahora en ningún lado se había conseguido definir de manera clara el concepto objeto, imagínense las dificultades para esclarecer el de aura. Esta palabra tampoco aparece en ninguna enciclopedia de historia del arte. En las enciclopedias generales se le describe como un "carisma misterioso" (en el siglo xviII, como "exhalación").

En 1936 Walter Benjamin publicó su multicitado ensayo "La obra de arte en la era de su reproducibilidad técnica". Él vio un cambio radical en la concepción artística con la reproducción de las obras de arte por medio de grabados de acero y madera en el siglo XIX, en particular mediante los nuevos medios técnicos — como la fotografía y la película. "La autenticidad de una cosa es la definición de todo, desde su origen hasta su tradicionalidad, desde su duración material hasta su testimonio histórico." ${ }^{8}$ Esto lo escribió en su momento y más adelante comprobó que "la técnica de reproducción deslinda lo repro-

6. "Gedachte unserer Vorstellung im Gegensatz zum Akt des Vorstellens"; Meyers Konversationslexikon, Leipzig/Viena, Bibliographisches Institut, I906.

7. "'objects' are in some way the thing we are willing to say we work with", Stephen Melville (ed.), The Lure of the Object, Williamstown, Sterling and Francine Clark Art Institute, 2005, p. VIII.

8. "Die Echtheit einer Sache ist der Inbegriff alles von Ursprung her an Tradierbaren, von ihrer materiellen Dauer bis zu ihrer geschichtlichen Zeugenschaft", Walter Benjamin, Das Kunstwerk im Zeitalter seiner technischen Reproduzierbarkeit, en Zeitschrift für Sozialforschung, I936 [Walter Benjamin, La obra de arte en la época de su reproducibilidad técnica, México, Ítaca, 2003]; véase también Rolf Tiedemann y Hermann Schweppenhäuser, Walter Benjamin: Gesammelte Schriften, Fráncfort del Meno, Suhrkamp/Insel, 1972-1989, p. 477. 
ducido del área de la tradición [...] y coloca en el lugar del suceso único al de enormes masas". P Para él, con la reproducibilidad técnica se comprometía el aura de las obras de arte y, con esto, el original mismo.

En la historia del arte se volvió frecuente, desde los años setenta, recurrir a las tesis de Benjamin, ya que particularmente con la tecnología e internet la reproducibilidad técnica de las obras de arte se ha incrementado millones de veces, aunque con ello se ignora casi siempre el contexto histórico del ensayo de Benjamin: el conflicto en 1935 entre el Frente Popular y los estalinistas franceses. ${ }^{10}$ La virtualización, así como la transformación digital de la obra de arte en columnas de números con ceros y unos, lleva — siguiendo a Benjamin-a la disolución de la obra de arte y provoca su multiplicación ilimitada. El original ya no es indispensable. Las reproducciones, que en apariencia se acercan al original, son en igual medida nuevamente repetibles en forma infinita.

Si se observa el comportamiento de los flujos de turistas ante obras de arte famosas en París, Florencia o Roma, surgen dudas sobre la validez de las tesis de Benjamin. Aparentemente, la reproducción masiva — mediante la foto y la película y ahora también por medio de internet- no afectó el aura del original, sino que incluso lo fortaleció. Veamos, por ejemplo, cómo millones de visitantes desfilan cada ańo en el Louvre ante la Mona Lisa, para ver al menos una vez el original de una de las pinturas más famosas del mundo, aun cuando se encuentre confinado tras gruesos vidrios que lo protegen de la lluvia de flashes de las cámaras de los turistas.

El aura es un componente de aquellas obras de arte, forma parte del canon turístico: largas filas se forman frente a la Galleria dell'Academia en Florencia, donde se puede apreciar el David de Miguel Ángel — cerca de un millón y medio de personas pasan por ahí cada año. Y al contrario, uno se encuentra casi completamente solo cerca de ahí, ante la Pietà del mismo artista, que fue colocada en el museo vecino de la catedral (Duomo), quizá porque se reprodujo menos. ¿Pero qué establece el aura de la obra de arte cuando, como en el caso de la Mona Lisa, el visitante en realidad no puede tomar nada como fehaciente, pues no sabe si lo que está detrás del vidrio es realmente el original? ¿Qué papel desempeña dicha autenticidad del objeto según Benjamin y el original hoy día?

9. "Die Reproduktionstechnik löst das Reproduzierte aus dem Bereich der Tradition ab [...] Sie setzt an die Stelle seines einmaligen Vorkommens sein massenweises". Idem.

Iо. Horst Bredekamp, Der simulierte Benjamin: Mittelalterliche Bemerkungen zu seiner Aktualität, en Andreas Berndt et al. (eds.), Frankfurter Schule und Kunstgeschichte, Berlín, s.e., I992, p. I20. 


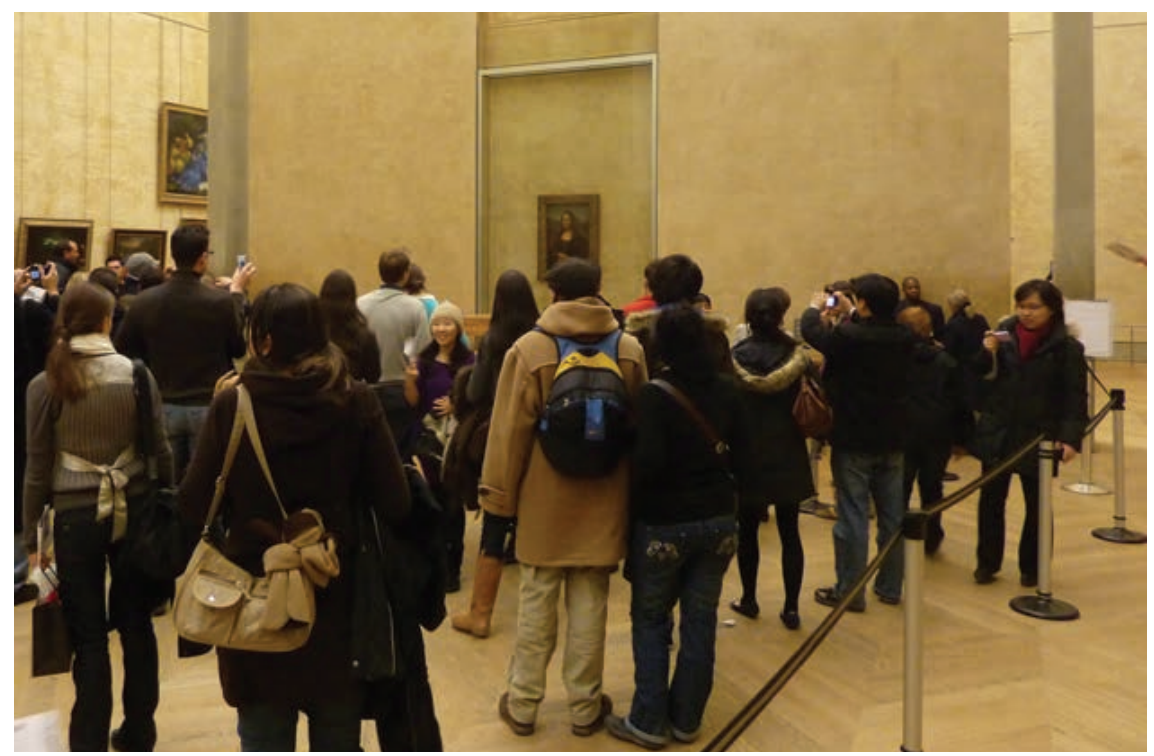

I. Visitantes frente a la Mona Lisa en el Museo del Louvre. Foto: G. Ulrich Grossmann.

En el arte contemporáneo se incrementan las obras de arte conceptuales, mientras el objeto material se aleja cada vez más en el pasado. Los museos se enfrentan a la pregunta por el objeto con relación al arte contemporáneo. El artista fluxus Ben Vautier expuso en 1962 una vitrina casi vacía, bajo cuya caja de cristal sólo se encontraba la ficha catalográfica; la descripción del objeto - escrita por el artista - colgaba arriba en la pared y decía rien (nada). Resulta inevitable preguntarse ¿qué es en este caso el objeto en el arte? ¿La vitrina del museo, la descripción del artista o la idea oculta? Detrás de la pregunta trivial ¿cómo se cataloga un objeto de esta naturaleza o cómo se asegura el préstamo? se expone el cuestionamiento del manejo con tal tipo de arte que rehúsa, a primera vista, el carácter tradicional de los museos y exposiciones, aunque es un arte que justamente buscó su camino hacia esa institución.

Más complicado resulta cuestionar obras de arte generadas en la red que, dependiendo del hardware de cada observador, son totalmente independientes de objetos tangibles. ¿Cuál es el objeto de dichas obras de arte que permanecen encerradas: video-arte, arte-internet, performance? Cada fotografía, cada impresión a color o screenshot puede ser sólo un mero recuerdo de la obra original. 


\section{G. ULRICH GROSSMANN}

¿Debemos suponer un arte sin objeto o hay siempre un objeto existente que actúa incluso para la obra o que facilita la acción del trabajo artístico? ¿ Se le están perdiendo los objetos a la historia del arte? Finalmente: ¿puede también un objeto virtual emitir un aura?

¿De qué manera se modifica la teoría de los objetos en la historia del arte como resultado de la virtualización? En sus dos siglos de existencia, la investigación sobre historia del arte desarrolló un sólido canon de métodos que durante décadas fueron válidos como base de la disciplina. Al centro se establecieron sobre todo los objetos en el sentido de Gegenstände, como pintura, escultura, gráfica y arquitectura. Si bien en un principio la historia del arte era principalmente una ciencia de ilustración en la que la base consistía más en la reproducción y menos en el original de la obra de arte — comenzando con los grabados del siglo XIx hasta la fotografía análoga del xx y los medios digitales en la actualidad-, ocasionalmente podría surgir la impresión de que el objeto detrás de la ilustración había perdido su significado. Pero ¿̨necesitamos todavía el objeto original? ¿Qué papel desempeña frente a esta posibilidad dicho original? A los museos, como entidades protectoras de objetos, el reto se les presenta cada día. La necesidad de desconfiar de las opiniones establecidas y de enfrentarse al objeto mismo no siempre está presente en la conciencia de todo investigador. Con frecuencia una opinión establecida en la investigación es tan determinante que se ignora comprobarla frente al objeto. Otro reto consiste —no sólo a través de los métodos establecidos al observar la obra (incluyendo la ciencia y la técnica) - en que siempre se exige un cuestionamiento y una conclusión. Los rayos x en sí mismos no tienen sentido en este contexto. En ocasiones hay que advertir de ello a los museos. El diálogo entre museos y universidades es especialmente importante: con frecuencia, los primeros tienen sus objetos aislados (por ejemplo, las pinturas de altares cuelgan solas como obras de galería en el conjunto de pinturas), mientras que las segundas están dispuestas a investigar la contextualización de los fragmentos, lo que representa el reto de los objetos museísticos, aunque para ello los museos tienen el acceso directo al objeto mismo.

Los desafíos mencionados respecto a una nueva teoría del objeto en la historia del arte conduce al inicio del texto: hay que admitir que el objeto es el Gegenstand central de la historia del arte, pero ésta no cuenta ni parcialmente con una teoría de los objetos, aunque opera de modo permanente con ese concepto.

Con esta temática se llevará a cabo el 33 Congreso Internacional de Historia del Arte. Después de las reuniones en Gran Bretaña (2000), Canadá (2004) 
y Australia (2008), en esta ocasión los congresistas recibirán la hospitalidad del Comité Nacional Alemán de Historia del Arte y del Museo Nacional Germánico (Germanisches Nationalmuseum) en la ciudad de Núremberg. Por primera vez —en I 32 años de historia del congresogran reunión que, siguiendo el reglamento respectivo del Comité Internacional de Historia del Arte, propone el marco temático. Por ello, apoyado también por una propuesta de Wolf Tegethoff (del Zentralinstitut für Kunstgeschichte, Múnich), se escogió el tema del "desafío del objeto" no sólo para desarrollar una teoría de los objetos, sino también para superar las barreras entre el arte de Europa y el de otros continentes. Entre tanto, es claro el interés global en este planteamiento temático, ya que no sólo se multiplicaron las solicitudes para este congreso en los cinco continentes, sino que también numerosas organizaciones desde América hasta Asia se dedicaron a este complejo tema. \$

N.B. Texto original en alemán, traducido al español por Karla Richterich. 